\title{
On the use of microwave radar devices in chronobiology studies: An application with Periplaneta americana
}

\author{
VITTORIO PASQUALI and PAOLO RENZI \\ Università di Roma “La Sapienza," Rome, Italy
}

\begin{abstract}
Modified motion detectors can be used to monitor locomotor activity and measure endogenous rhythms. Although these devices can help monitor insects in their home cages, the small size of the animals requires a very short wavelength detector. We modified a commercial microwave-based detection device, connected the detector's output to the digital input of a computer, and validated the device by recording circadian and ultradian rhythms. Periplaneta americana were housed in individual cages, and their activity was monitored at $18^{\circ} \mathrm{C}$ and subsequently at $28^{\circ} \mathrm{C}$ in constant darkness. Time series were analyzed by a discrete Fourier transform and a chi-square periodogram. $\mathrm{Q}_{10}$ values and the circadian free-running period confirmed the data reported in the literature, validating the apparatus. Moreover, the spectral analysis and periodogram revealed the presence of ultradian rhythmicity in the range of $1-8 \mathrm{~h}$.
\end{abstract}

Locomotor activity is a useful variable for monitoring the functions of biological clocks. For long-term monitoring, automatic detection is required.

Technology for automated detection and recording of locomotor activity has evolved considerably; small mammals and insects have been monitored with ultrasound (Akaka \& Houck, 1980), infrared beams (Clarke, Smith, \& Justesen, 1985), stabilimeters (Zeier \& Tschannen, 1968), running wheels (Roberts, 1956), capacity transducers (Schechter, Dutky, \& Sullivan, 1963), sound detectors (Jones, 1964), and radars (Kropveld \& Chamuleau, 1993; Martin \& Unwin, 1980; Vanuytven, Vermeire, \& Niemegeers, 1979). The radar-based methods have a number of advantages: They are not intrusive, produce output suitable for direct computer analysis, and are adaptable to different conditions. Radar motion detectors can provide automatic monitoring of an animal's general locomotor activity in its home cage without disturbing the pattern of its normal behavior or initiating the spurt of exploration occasioned by transfer to a novel environment.

Microwave radar was used for the first time with insects by Buchan and Sattelle (1979) for quantitative analysis of activity. These actometers have been shown to be sensitive

This work was supported in part by the Istituto Superiore di Sanità (Italy) and in part by the Università di Roma "La Sapienza." We thank Michele Nino Maroli for his support of the research, Fabio Ferlazzo and Francesca D'Olimpio for suggestions on the text and revision, Pietro Fermani for modifications to the electronic circuit, and Benjamin Kenward and Matteo Ippoliti for the English revision. Correspondence concerning this article should be addressed to V. Pasquali, Dipartimento di Psicologia, Università di Roma "La Sapienza," Via dei Marsi, 78, 00185 Rome, Italy (e-mail: vittorio.pasquali@uniroma1.it).

Note-This article was accepted by the previous editor, Jonathan Vaughan. enough to record flight and locomotor activity of individual insects such as tsetse flies (Van der Goes van Naters, Den Otter, \& Maes, 1998), moths (Den Otter, De Cristofaro, Voskamp, \& Rotundo, 1996; Renou, Berthier, Desbarats, Van der Pers, \& Guerrero, 1999), Anopheles mosquitos (Van de Broek, Den Otter, \& Van der Pers, 1999), and fruit flies (Knoppien, Van der Pers, \& Van Delden, 2000). In the present study, we describe a homemade microwave radar device for monitoring locomotor activity in insects and small mammals. Locomotor activity is an arbitrarily defined unit of measurement that depends on the resolution of the detection system and the objectives to be attained in a given experiment. If the experimenter wishes to define only gross body movements as signals and maintenance behaviors as noise, then only very sophisticated and expensive activity monitors will be satisfactory.

The radar-based activity monitoring described here is a modification of the system developed and validated by our group (Conte, D’Olimpio, \& Renzi, 1995; D'Olimpio, Conte, \& Renzi, 1996; D’Olimpio \& Renzi, 1997) to study the behavior of mice. The primary contribution of the present system involves adaptation of a commercially available radar device for use in a home alarm system. The advantages of our device are that it is easily adaptable to different experimental conditions and allows monitoring of the animal in its cage. Low microwave radiation with

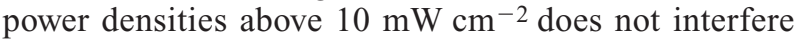
with insect behavior; in contrast, the ultrasound device does interfere because of ultrasound-sensitive ears and evasive flight maneuvers in response to pulsed ultrasound are highly developed in species distributed among five insect orders (Hoy, 1992). We modified the original approach to adapt this radar system to smaller animals, such as cockroaches, in our experimental system applied to a chronobiological study. 
To maximize fitness, organisms must synchronize their activities with their physical environment and with other organisms. Since environmental change is cyclical, almost all behaviors (e.g., feeding, mating, locomotion) are in temporal rhythmicity. Adult male cockroaches express robust circadian rhythmicity in locomotion under constant darkness. Locomotor circadian rhythm of adult cockroaches is controlled by a "biological clock," which is temperature compensated. $\mathrm{Q}_{10}$ is the ratio of the period at a given temperature $X$ to that of the period at temperature $X+10^{\circ}$. The periods of circadian rhythm are marked by a high degree of temperature compensation, with $\mathrm{Q}_{10} \sim 1$. We identified reliable parameters of cockroach circadian rhythms, confirming the efficiency of our radar-based device.

\section{CONSTRUCTION, CALIBRATION, AND TESTING}

Locomotor activity was recorded automatically by microwave radars (Mw-12, 9.9-GHz, Lince Italia) linked to a personal computer (IBM compatible). The radar wavelength is $3 \mathrm{~cm}$, and moving objects smaller than the wavelength are detected only under accurate regulations of sensitivity. In a commercial device such as ours, the sensitivity is controlled by a trimmer resistor with a narrow range of variation $(22 \mathrm{k} \Omega)$, which we changed to a $100-\mathrm{k} \Omega$ trimmer to obtain a finer scale of resistance for broader control of the sensitivity. Radar is connected to the computer by a standard digital I/O board (PIO-12, Keithley Instruments). The input signal for the $\mathrm{I} / \mathrm{O}$ board was led to the LED connection. An LED signaling the motion detection is always present in this device. A simple program written in Quick Basic for PCs read the channels of the I/O board. The parameters (sampling frequency of 10-2,000 msec, collected interval, length of the experiment) were easily modifiable. The number of radars supported by the device depends only on the number of channels in the I/O board. It is important to make sure that (1) there is no interference between the radars, (2) the same value of sensitivity is used for both radars, (3) all the radars measure the same quantity of movements, and (4) this setting does not drift over time. We also shielded the adjacent radars and set the trimmer to $12 \mathrm{k} \Omega$ (at this value the radar responded to whole-body movements and not to movements of body parts).

In the procedure for checking the system, we used a standardized moving object. A small, 2-rpm synchronous electric motor with a $15-\mathrm{cm}$-long arm was mounted $50 \mathrm{~cm}$ from the radars. A $2 \times 2 \mathrm{~cm}$ aluminum sheet (the target) was attached to the arm. Between the electric motor and the radar was a metal shield that covered the rotation of the arm for $270^{\circ}$. The radar was focused on a window of $90^{\circ}$. With this arrangement, the target was visible to the radars for a total of $15 \mathrm{sec}$ every two revolutions $(7.5 \mathrm{sec}$ per revolution).

The correctness of the calibration of each radar's sensitivity was checked in terms of the number of signals counted for it by the software. ${ }^{1}$ During the check, we used a sampling frequency of $1,000 \mathrm{msec}$; therefore, the software detected a maximum of $1 \mathrm{signal} / \mathrm{sec}$, or about $15 / \mathrm{min}$. Each minute, the totals of the acquisition were saved to the hard disk; the length of the recording was $540 \mathrm{~min}$. We expected a count of 8,100 signals $(15$ signals $/ \mathrm{min} \times$ $540 \mathrm{~min})$. The actual counts were 6,423 for radar 1 and 5,971 for radar2, with accuracies of $79.2 \%$ and $73.7 \%$, respectively. For statistical analysis, we summed the data every $30 \mathrm{~min}$. No significant statistical difference was present between the series recorded from the two radars in the test condition: For radar1, the mean $(M)$ plus or minus standard deviation $(S D)$ was $356.83 \pm 88.58$; for radar2 it was $331.72 \pm 98.49[t(34)=0.80, p=.42]$. The comparison between the first and second halves on the same radar also showed no statistically significant difference: For radar $1, M \pm S D=359.11 \pm 80.55$ for the first half and $354.55 \pm 100.86$ for the second half $[t(16)=$ $0.10, p=.91]$; for radar2, $M \pm S D=342 \pm 100.61$ for the first half and $321.44 \pm 101.26$ for the second half $[t(16)=0.43, p=.67]$. We also verified that the radars did not yield false signals in the absence of movement.

\section{VALIDATION OF THE APPARATUS}

\section{Subjects}

Nine male Periplaneta americana obtained from the insectarium of the Istituto Superiore di Sanità (Italy) were housed individually in transparent plastic boxes $(15 \times$ $15 \times 10 \mathrm{~cm}$; see Figure 1$)$. Only males were selected, to avoid interference of the female hormonal cycle with locomotor activity (Tsai \& Lee, 2000). The insects were kept in continuous darkness (12:12-h dark:dark, DD), and the temperature was maintained constant at $23^{\circ} \mathrm{C}$, with food and water provided ad lib.

\section{Procedure}

Before recording began, all the insects remained for over 30 days in habituation with photoperiod DD and temperature at $18^{\circ} \mathrm{C}$. After the period of habituation, we recorded locomotor activity for 7 days at $18^{\circ} \mathrm{C}$. We then raised the temperature to $28^{\circ} \mathrm{C}$, and after a new, 20-day period of habituation we recorded locomotor activity for another 7 days.

\section{Data Analysis}

All time series were smoothed (three-point moving average), and the linear trend was removed before the analyses were made. We applied two different analyses: (1) Power spectra were computed for each subject by means of the discrete Fourier transform (DFT) algorithm. Smoothed estimation of the spectra was obtained by means of the Parzen lag window. A one-sample Kolmogorov-Smirnov test was used to test the hypothesis that the spectra originated from a random process (white noise). In spectra that were significantly different from white noise, spectral density values above 2.81 SDs were considered significant peaks (Conte, Ferlazzo, \& Renzi, 1995). (2) To estimate the circadian and ultradian periods observed in the spectral analysis, we analyzed the data with the use of the 


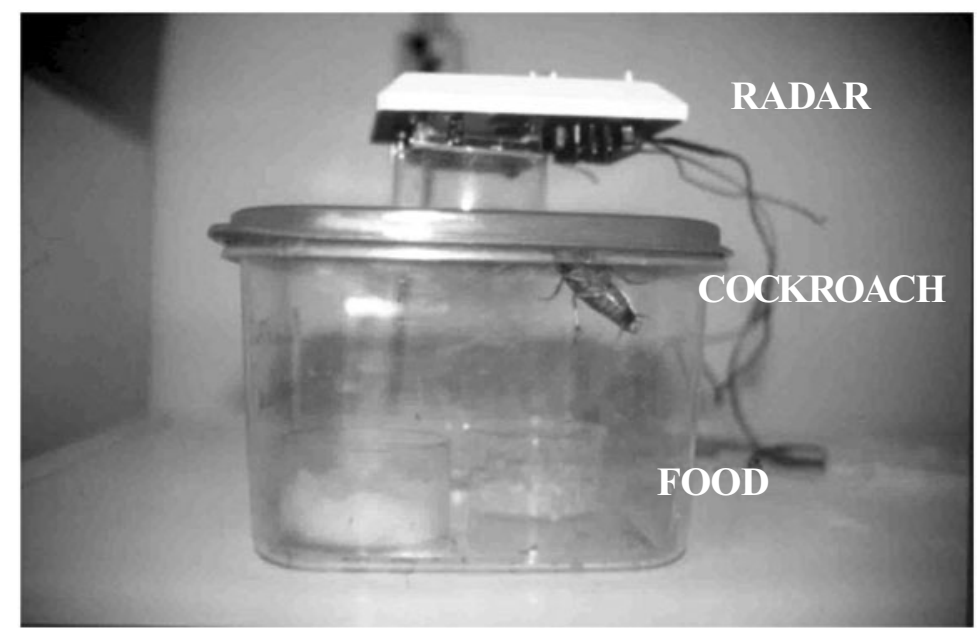

Figure 1. Experimental cage with radar above.

chi-square periodogram of Sokolove and Bushell (1978) over a trial-period range of $22-26 \mathrm{~h}$ for the circadian and $1-8 \mathrm{~h}$ for the ultradian period, at a .05 significance level.

\section{RESULTS}

The radar device recorded movements of 9 cockroaches $4 \mathrm{~cm}$ in length, housed in independent cages. Measurements were performed in 7-day periods to monitor ultradian rhythms, and circadian rhythms were as clear as they were with a longer period (15 days, results not shown).

The power spectrum computed for individual cockroaches and the periodogram analysis revealed significant peaks for both circadian and ultradian rhythms in locomotor activity in free running (DD).

Periodogram analysis showed a circadian rhythmicity; the mean free-running period $(\tau)$ at $18^{\circ} \mathrm{C}( \pm S E)$ was $23.7 \pm 0.53 \mathrm{~h}$ (see Table 1). Simultaneously, we calculated the $\mathrm{Q}_{10}$ value $\left(\mathrm{Q}_{10}=\tau 18^{\circ} \mathrm{C} / \tau 28^{\circ} \mathrm{C}\right)$, and the mean was $0.94 \pm 0.02$ (see Figure 2). The data on the circadian rhythmicity were also confirmed by the DFT, which revealed the presence of more significant peaks at $24 \mathrm{~h}$ in all the insects. The circadian power spectrum was lower at $28^{\circ} \mathrm{C}$ than at $18^{\circ} \mathrm{C}$ (Figure 3 ).

Table 1

Circadian Free-Running Period $(\tau)$ in Continuous Darkness and $\mathbf{Q}_{\mathbf{1 0}}$

\begin{tabular}{clll}
\multicolumn{4}{c}{ and $\mathbf{Q}_{\mathbf{1 0}}$} \\
\cline { 2 - 3 } Cockroach & $18^{\circ} \mathrm{C}$ & $28^{\circ} \mathrm{C}$ & $\mathrm{Q}_{10}$ \\
\hline 1 & 23.8 & 24.4 & 0.98 \\
2 & 23.6 & 25.8 & 0.91 \\
3 & 20.0 & 25.4 & 0.79 \\
4 & 25.6 & 23.8 & 1.08 \\
5 & 23.8 & 25.6 & 0.93 \\
6 & 23.2 & 26.0 & 0.80 \\
7 & 24.4 & 25.0 & 0.98 \\
8 & 25.2 & 25.8 & 0.98 \\
9 & 23.4 & 26.0 & 0.90 \\
\hline
\end{tabular}

In addition to the circadian rhythms, ultradian rhythms in locomotor activity occurred in every cockroach, and we were able to detect them with the spectral analysis. DFT showed that in all the insects significant peaks are present in the range of $1-8 \mathrm{~h}$. To evaluate the reliability/repeatability of these rhythms, we computed the spectral analysis separately on the first and second halves of the original data, and we found the same rhythms again (Figure 4).

We observed peaks with a high spectral power between 100 and $200 \mathrm{~min}$, at about $5 \mathrm{~h}$, and at about $8 \mathrm{~h}$. These periods were found at both $18^{\circ} \mathrm{C}$ and $28^{\circ} \mathrm{C}$. A comparison between the spectra obtained from measurements at both temperatures revealed no significant difference (Figure 3). Generally, the power spectrum in the range of $1-8 \mathrm{~h}$ is greater at $28^{\circ} \mathrm{C}$ than at $18^{\circ} \mathrm{C}$.

Data revealed the presence of temperature-compensated periods. All the cockroaches showed a $\mathrm{Q}_{10}$ of $\sim 1$ for the circadian rhythm. In the ultradian band, most of the cockroaches (about $80 \%$ ) showed temperature-compensated periods at $8 \mathrm{~h}$ and $5 \mathrm{~h}$, whereas only a small percentage showed them at less than $5 \mathrm{~h}$ (see Figure 2).

\section{DISCUSSION}

In this study, we have described a radar actometer with which the locomotor activity of a single insect can be recorded.

We used this actometer to measure circadian and ultradian rhythmicity in the locomotor activity of Periplaneta americana. Unlike similar devices, our system is characterized by low cost, different sensitivities for animals of different sizes, the ability to record general locomotor activity, and monitoring of animals in their cages.

These results on circadian rhythms agreed with our other results: We found a period of $24.5 \mathrm{~h}$ in DD at $22^{\circ} \mathrm{C}$ (Renzi \& Pasquali, 2000). All these data are in agreement with the data presented in the literature (Saunders, 1976). Also, the $\mathrm{Q}_{10}$ showed a value of $\sim 1$, which is coherent with one of the five "rules of Pittendrigh" (Pittendrigh, 1966) 


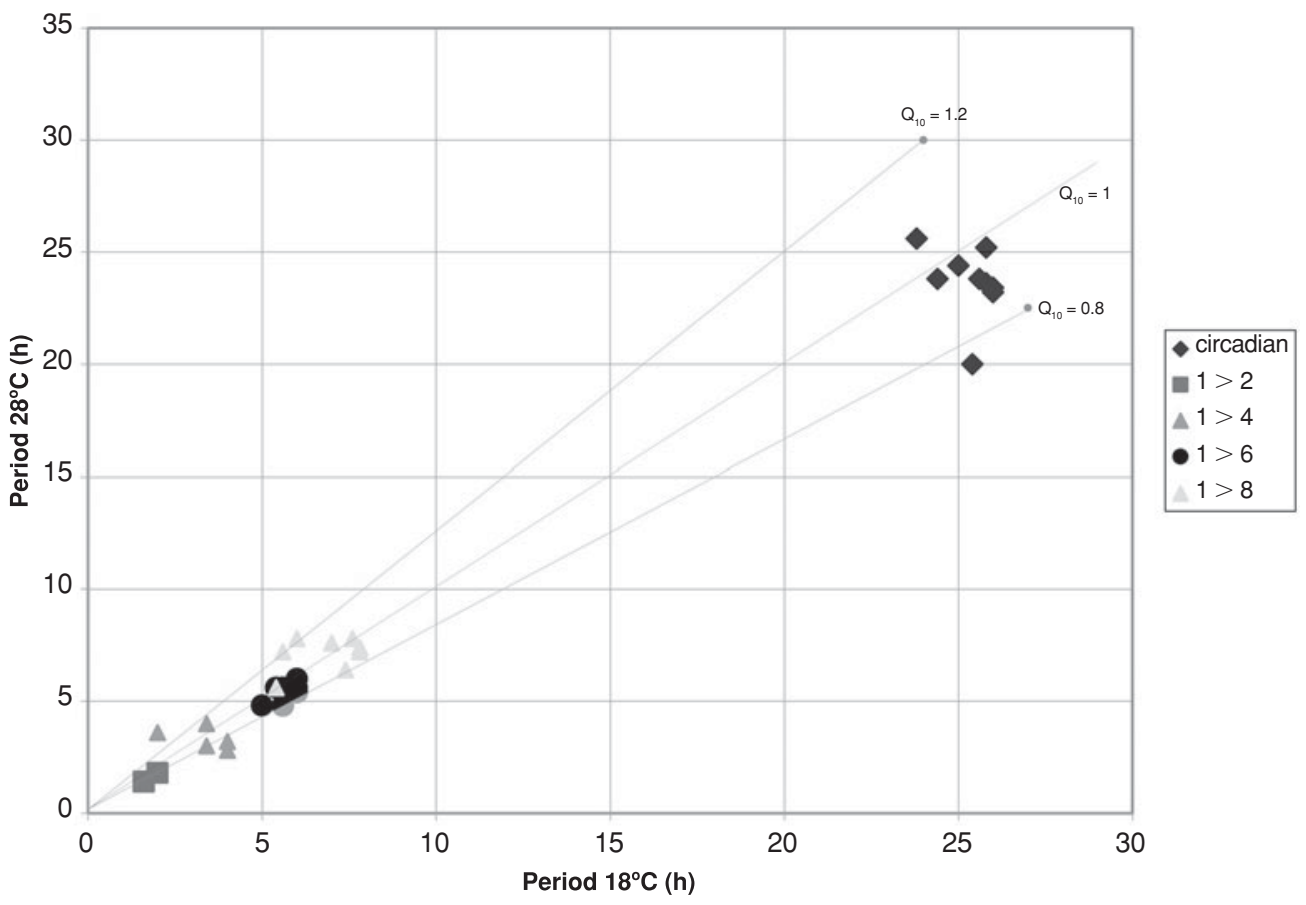

Figure 2. Bands of frequencies that are temperature compensated. Each point represents a cockroach; all animals show a compensation in temperature of the circadian rhythm. In the ultradian bands, few cockroaches are below $5 \mathrm{~h}$ and most are above $5 \mathrm{~h}$. The center line represents $Q_{10}=1$, and the upper and lower lines represent the limits of significance.

for demonstrating an endogenous clock: “ . . Q $\mathrm{Q}_{10}$ between 0.8 and $1.2 \ldots$ is an absolute functional prerequisite for a clock mechanism" (Saunders, 1976, p. 3). Moreover, we have compared these data with old data obtained from the monitoring of cockroaches with an infrared system (Pasquali, 2001). The visual comparison of the actograms did not show macroscopic differences (Figure 5). A comparison between the circadian periods in free running de-

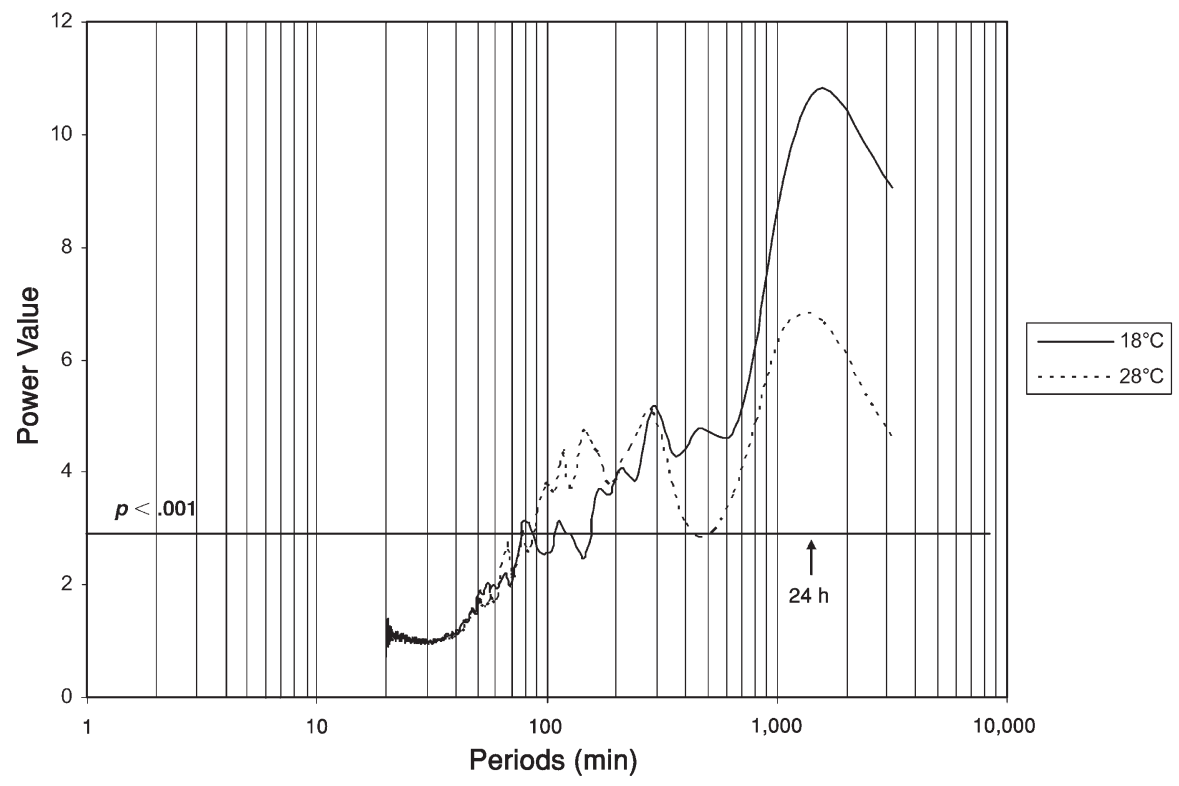

Figure 3. Mean power spectra at $18^{\circ} \mathrm{C}$ and $28^{\circ} \mathrm{C}$ in continuous darkness. Power values are shown on the $y$-axis; periods (in minutes) on a logarithmic scale are shown on the $x$-axis. 

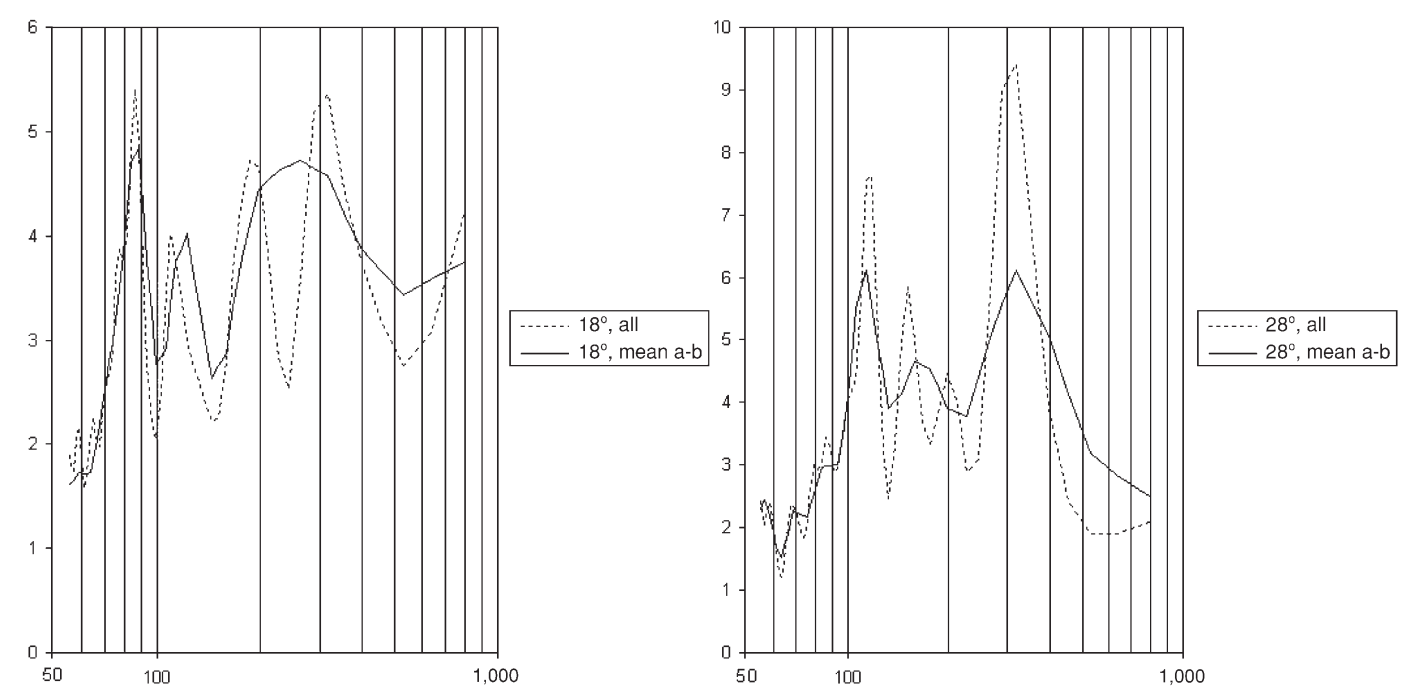

Figure 4. Comparison between the spectral analysis of all recordings and the mean of the spectral analysis of the first and second halves of the same recording (Cockroach 1).

tected with infrared $(24.5 \pm 0.50 \mathrm{~h})$ and radar $(23.7 \pm$ $0.53 \mathrm{~h} ; M \mathrm{~s} \pm S E \mathrm{~s})$ did not show significant differences $[t(11)=-0.95, p=.36]$. Both of the systems showed efficacy, but the radar showed great sensitivity (Figure 5).

This device and this type of data sampling allowed extended spectral analyses to reveal the presence of ultradian rhythmicity. Spectral analysis demonstrated significant peaks in the band of 1-8 $\mathrm{h}$ with the recurrence of a 200min period. Such a time period was similarly observed in other studies on ultradian rhythms (Pasquali, Carola, Migliore, Kovacev, \& Renzi, 2003; Pasquali \& Renzi, 2002).
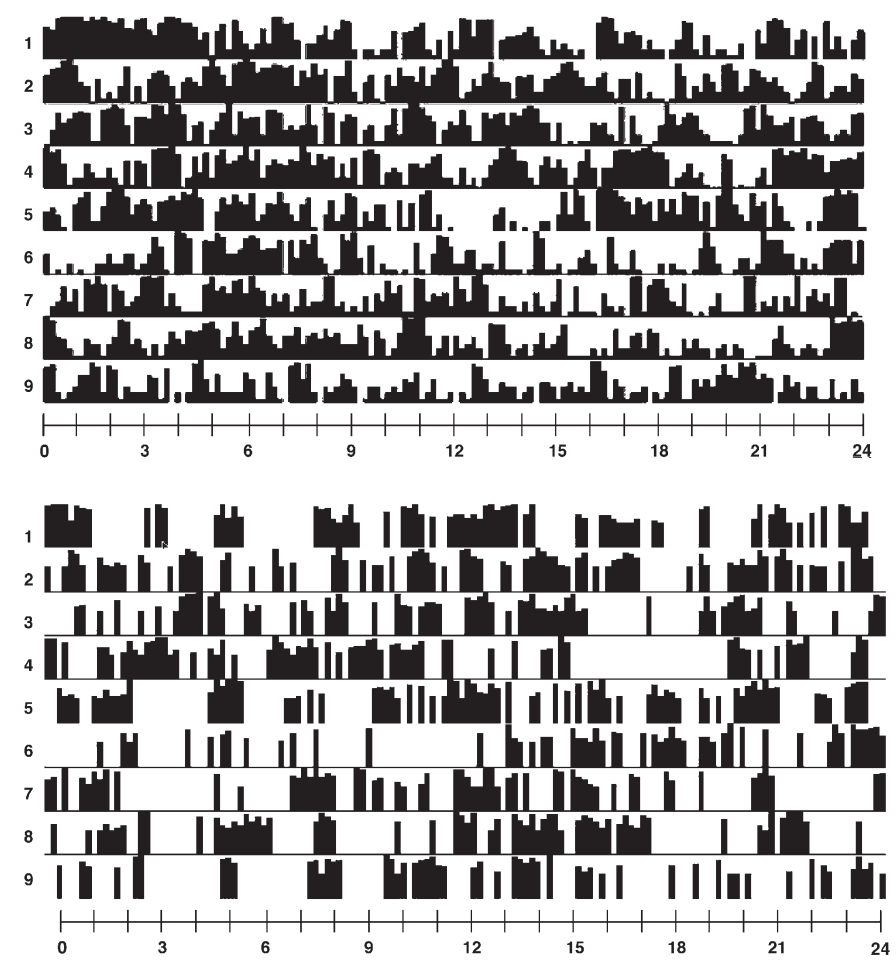

Figure 5. Activity records in two different experiments, with radar (top) and infrared beam (bottom). The actograms below show the locomotor activity of two cockroaches at 10-min intervals. 


\section{REFERENCES}

AKaKa, W. H., \& Houck, B. A. (1980). The use of an ultrasonic monitor for recording locomotor activity. Behavior Research Methods \& Instrumentation, 12, 514-516.

Buchan, P. B., \& Sattelle, D. B. (1979). A radar-Doppler autocorrelation analysis of insect activity. Physiological Entomology, 4, 103-109.

Clarke, R. L., Smith, R. F., \& Justesen, D. R. (1985). An infrared device for detecting locomotor activity. Behavior Research Methods, Instruments, \& Computers, 17, 519-525.

Conte, S., D’Olimpio, F., \& Renzi, P. (1995). Uno strumento per la registrazione dell'attività motoria [An instrument for the recording of motor activity]. Rivista di Psicologia, 80, 69-70.

Conte, S., Ferlazzo, F., \& Renzi, P. (1995). Ultradian rhythms of reaction times in performance in vigilance tasks. Biological Psychology, 39, 159-172.

Den Otter, C. J., De Cristofaro, A., Voskamp, K. E., \& Rotundo, G. (1996). Electrophysiological and behavioural responses of chestnut moths, Cydia fagiglandana and $C$. splendana (Lep., Tortricidae), to sex attractants and odours of host plants. Journal of Applied Entomology, 120, 413-421.

D’Olimpio, F., Conte, S., \& Renzi, P. (1996). Ritmi ultradiani di attività motoria in topi tenuti in condizioni di luce alternata e luce costante [Ultradian rhythms of motor activity in mice kept in conditions of alternate light and constant light]. In Proceedings of the Italian Association of Psychology (Experimental Chapter) National Conference (pp. 128-129). Capri: DL Comunicazioni.

D’Olimpio, F., \& RenzI, P. (1997). Effetti dell'attività sui ritmi biologici dei roditori [Effects of activity on the biological rhythms of rodents]. In Proceedings of the Italian Association of Psychology (Experimental Chapter) National Conference (pp. 129-130). Capri: DL Comunicazioni.

Hoy, R. R. (1992). The evolution of hearing in insects as an adaptation to predation from bats. In D. B. Webster, R. R. Fay, \& A. N. Popper (Eds.), The evolutionary biology of hearing (pp. 115-129). New York: Springer.

JoNes, M. D. R. (1964). The automatic recording of mosquito activity. Journal of Insect Physiology, 10, 343-351.

Knoppien, P., Van der Pers, J. N. C., \& Van Delden, W. (2000). Quantification of locomotion and the effect of food deprivation on locomotor activity in Drosophila. Journal of Insect Behavior, 13, 27-43.

Kropveld, D., \& Chamuleau, R. (1993). Doppler radar device as a useful tool to quantify the liveliness of the experimental animal. Medical \& Biological Engineering \& Computing, 31, 340-342.

Martin, P. H., \& Unwin, D. M. (1980). A microwave doppler radar activity monitor. Behavior Research Methods \& Instrumentation, 12, 517-520.

PASQUALI, V. (2001). Evidenze sperimentali circa la presenza di ritmicità ultradiana nell 'attività locomotoria di insetti [Experimental evidence of the presence of ultradian rhythmicity in the locomotor activity of insects]. Unpublished master's thesis, Università degli Studi di Roma "La Sapienza," Rome.

Pasquali, V., Carola, V., Migliore, M., Kovacev, I., \& Renzi, P. (2003). Ritmi circadiani ed ultradiani di attività locomotoria in ceppi inbred di topo [Circadian and ultradian rhythms of locomotor activity in inbred mice] [Abstract]. In Proceedings of the Italian Society of Neuroscience National Conference (p. 32). Pisa: SINS.

PAsquali, V., \& RenZI, P. (2002). Study on endogenous rhythmicity and social rhythmicity of activity in Formica lugubris. Insect Social Life, 4, 27-32.

PitTENDRIGH, C. S. (1966). The circadian oscillation in Drosophila pseudoobscura pupae: A model for the photoperiodic clock. Zeitschrift für Pflanzenphysiologie, 54, 257-307.

Renou, M., Berthier, A., Desbarats, L., Van Der Pers, J., \& GuerRERO, A. (1999). Actographic analysis of the effects of an esterase inhibitor on male moth responses to sex pheromone. Chemical Senses, 24, 423-428.

RenZI, P., \& PASQUALI, V. (2000). Presenza di ritmi ultradiani nell'attività locomotoria in Formica pratensis e Periplaneta americana [Presence of ultradian rhythms in the locomotor activity in Formica pratensis and Periplaneta americana] [Abstract]. In Proceedings of the Italian Society of Ethology National Conference (p. 73). San Giuliano Terme: Edizioni ETS.

RoBerTs, S. K. D. F. (1956). "Clock” controlled activity rhythms in the fruit fly. Science, 124, 172.

SAUNDERS, D. S. (1976). Insect clocks. Oxford: Pergamon.

Schechter, M. S., Dutky, S. R., \& Sullivan, W. N. (1963). Recording circadian rhythms of the cockroach with a capacity-sensing device. Journal of Economic Entomology, 56, 76-79.

Sokolove, P. G., \& Bushell, W. N. (1978). The chi square periodogram: Its utility for analysis of circadian rhythms. Journal of Theoretical Biology, 72, 131-160.

Tsai, C., \& LeE, H. (2000). Circadian locomotor rhythm masked by the female reproduction cycle in cockroaches. Physiological Entomology, 25, 63-73.

Van de Broek, I. V. F., Den Otter, C. J., \& Van der Pers, J. N. C. (1999). Actometers for evaluating mosquito activity: Daily activity and stimulus-induced activation. In Proceedings of the Section Experimental and Applied Entomology of the Netherlands Entomological Society (Vol. 10, pp. 85-90). Amsterdam: Nederlandse Entomologische Vereniging.

Van der Goes van Naters, W. M., Den Otter, C. J., \& Maes, F. W. (1998). Olfactory sensitivity in tsetse flies: A daily rhythm. Chemical Senses, 23, 351-357.

Vanuytven, M., Vermeire, J., \& Niemegeers, C. J. E. (1979). A new motility meter based on the Doppler principle. Psychopharmacology, 64, 333-336.

ZEIER, H., \& Tschannen, G. (1968). A new device for measuring general locomotor activity in instrumental conditioning situations. Journal of the Experimental Analysis of Behavior, 11, 63-64.

\section{NOTE}

1. The latest version of the software is available as freeware from vittorio.pasquali@uniromal.it.

(Manuscript received July 28, 2003; revision accepted for publication December 6, 2004.) 